\title{
Como as crianças estão se apropriando das Tecnologias Digitais na Primeira Infância?
}

\author{
Patrícia F. da Silva', Crediné S. de Menezes', Léa da Cruz Fagundes ${ }^{1}$ \\ 'Programa de Pós Graduação em Informática na Educação - Universidade Federal do Rio Grande do Sul (UFRGS) \\ Porto Alegre - RS - Brasil \\ \{patriciasilvaufrgs, credine, leafagundes\}@gmail.com
}

\begin{abstract}
This resume describes a thesis research developed in the Graduate Program in Informatics in Education at the Federal University of Rio Grande do Sul, which investigated the use and appropriation of digital technologies and the way in which children from the age of 7 months to 7 years of age perceive the attractiveness technologies. The methodology used was the application of piagetian tests and later the accomplishment of tests with use of technological resources. During the research, it was possible to observe that technologies allow children to perceive things more easily than when using concrete material.
\end{abstract}

Resumo. Este resumo descreve uma pesquisa de tese desenvolvida no Programa de de Pós-Graduação em Informática na Educação na Universidade Federal do Rio Grande do Sul, que investigou sobre o uso e apropriação das tecnologias digitais e o modo com que crianças da faixa etária de 7 meses a 7 anos de idade percebem os atrativos oferecidos pelas tecnologias. A metodologia utilizada foi a aplicação de provas piagetianas e posteriormente a realização de provas com uso de recursos tecnológicos. Durante a pesquisa, foi possivel observar que as tecnologias possibilitam à crianças perceber as coisas de modo mais fácil do que quando utilizado o material concreto.

\section{Introdução}

Atualmente, percebe-se que crianças, adolescentes, jovens e adultos estabelecem uma relação muito dinâmica com smartphones e tablets, fazendo com que estes utensílios sejam itens indispensáveis no seu dia-a-dia.

De acordo com os indicadores apontados através da pesquisa realizada pelo Comitê Gestor da Internet (CGI) e o Centro Regional de Estudos para o Desenvolvimento da Sociedade da Informação (Cetic.br), a TIC KIDS ONLINE - Brasil de 2015, 80\% são usuários da internet, utilizando de forma intensa, com acesso mais de uma vez por dia. $\mathrm{O}$ principal dispositivo para acesso a rede é o telefone celular: - $83 \%$ acessam por meio dele, 1 em cada 3 crianças ou adolescentes acessam a internet somente por meio do telefone, o equivalente a $31 \%$ da amostra.

Nesta perspectiva, é importante pensar na forma com que as tecnologias chegam até as crianças e como estão despertando seu interesse, bem como averiguar como percebem elementos com o uso das tecnologias digitais que não percebem ao manipular objetos concretos.

Visando encontrar respostas para esta problemática, uma pesquisa de tese foi desenvolvida com crianças de de 7 meses a 7 anos de idade, observando como que elas estavam percebendo os atrativos oferecidos pelas tecnologias digitais.

Pretende-se com este resumo, apresentar alguns dos resultados que foram obtidos. Este trabalho está estruturado da seguinte forma: introdução, metodologia de trabalho, 
referencial teórico utilizado, uso das provas piagetianas e dos recursos tecnológicos, e para finalizar os resultados obtidos e as referências.

\section{Metodologia de trabalho: o uso do Método Clínico, as provas piagetianas e as aproximações com as tecnologias digitais}

Piaget elaborou um grande número de provas para constatar o progresso do desenvolvimento cognitivo de crianças e adolescentes em relação à conservação, seriação, volume, massa, dentre tantas outras. Nessas investigações, desenvolveu o Método Clínico, em que é possível identificar como o sujeito evolui sobre determinadas noções.

O Método Clínico caracteriza-se pela coleta de dados pela proposição de atividades específicas, observação, registro e análise de diálogos com a criança; estes serão mediados pelo experimentador, visando seguir seu pensamento sem perder nenhum detalhe, mediante à análise dos dados que foram registrados (Deval, 2002).

O estudo dos dados obtidos, trata-se de um estudo múltiplo inspirado pelo Método Clínico (Piaget, 1975). Optou-se pela inspiração no Método Clínico, devido à variedade de opções na observação e coleta de dados, a qual oportuniza uma diversidade de estratégias para o registro.

Diante da observação de crianças foi investigado como elas estão se apropriando das tecnologias digitais, bem como percebem os atrativos oferecidos por estas ferramentas, verificando se a exploração do mundo digital se equivale em termos intelectuais à exploração de objetos concretos.

\section{Referencial Teórico: os estágios de desenvolvimento conforme Piaget}

Piaget (1974), ao falar de Epistemologia Genética salienta que o conhecimento é construído a partir da interação entre o sujeito e o objeto. Durante suas pesquisas Piaget elaborou um grande número de provas para constatar o progresso do desenvolvimento cognitivo de crianças e adolescentes em relação à conservação, seriação, volume, massa, dentre tantas outras.

Conforme Kamii (s.d), as contribuições de Piaget constituem-se nas ideias sobre os períodos de desenvolvimento da criança, bem como questões relacionadas à epistemologia, conhecimento e como se aprende. A seguir serão abordadas as principais características sobre os estágios de desenvolvimento conforme a teoria de Piaget e de acordo com a faixa etária das crianças observadas.

\subsection{O Período Sensório Motor (0 a mais ou menos 2 anos)}

Primeiro período da criança que vai do nascimento até mais ou menos os 2 anos. É um estágio em que não estão presentes as representações, a linguagem e os conceitos, pois devido a falta da função simbólica, a criança ainda consegue fazer estas representações.

Durante este período, suas ações consistem em coordenar entre si percepções e movimentos sucessivos, os quais são reconstituídos pelo pensamento. Por volta do final do segundo ano de vida, a criança começa a adquirir a linguagem sistematicamente, antes disso ela somente consegue imitar determinadas palavras e atribui a elas uma significação mais global.

A linguagem é adquirida ao mesmo tempo em que o símbolo é formado, sendo que ao empregar signos e símbolos presume-se que a criança esteja apta, pois esta ação se mostra 
VIII Congresso Brasileiro de Informática na Educação (CBIE 2019)

Anais do XXV Workshop de Informática na Escola (WIE 2019)

totalmente nova diante de outras condutas sensório-motoras em que elarepresenta uma coisa por outra.

\subsection{O Período Pré-Operatório (2 a mais ou menos 7 anos)}

Caracteriza-se pelo primeiro estágio da inteligência pré-conceitual, pré-conceitos ou raciocínio pré-conceitual, quando a linguagem começa a aparecer até mais ou menos 4 anos. Neste estágio, o objeto se internaliza e é lembrado pela criança, mesmo após o seu desaparecimento.

A criança reconstrói o objeto, o espaço e o tempo, categorias lógicas de classes e de relações no plano de representação. Os estágios entre os 2 e 7 anos tornam-se uma extensão dos estágios sensórios-motores, formando as bases das posteriores operações concretas.

Neste estágio, a criança apresenta dificuldades em elaborar relações compostas entre si, é difícil chegar a reversibilidade, pois a ação continua sendo traduzida com o único sentido da imagem e também a assimilação é centrada na percepção.

\subsection{O Período das Operações concretas (7 a mais ou menos 11-12 anos)}

O estágio das operações concretas é caracterizado pelo aparecimento das operações lógico-aritméticas e espaço-temporais. As operações sofrem equilibrações rápidas e às vezes até inesperadas, causando alterações nas noções de um sistema.

Dos 7 a 11-12 anos observa-se a reversibilidade adquirida, operações de classificação e de seriação que se elaboram ao mesmo tempo em que as invariantes de substância são constituídas, peso e volume, levam a criança a pensar com maior mobilidade e realidade concreta. A criança neste estágio opera sobre a possibilidade de observar o concreto, não levando em consideração hipóteses e deixando-se determinar pelo que é mais provável.

\section{Desenvolvimento da pesquisa: as provas piagetianas e uma aproximação com materiais digitais}

Participaram desta pesquisa, 2 (duas) crianças de cada faixa etária, dos 7 (sete) meses aos 7 (sete) anos, totalizando em 16 (dezesseis) crianças.

Para a escolha, foram selecionadas crianças com idades distintas, que utilizavam as tecnologias digitais, de diferentes classes sociais. A interação com sujeito foi organizada em três momentos: aplicação da prova ou verificação de observações realizadas por Piaget; aplicação de uma atividade utilizando tecnologias digitais e por fim, uma conversa com os pais para obter mais informações sobre a criança.

As observações realizadas e as provas de Piaget, foram de acordo com a faixa etária dos sujeitos. Para as crianças a partir de 7 meses até foi realizada a prova de permanência de objetos e imitação, posteriormente foi utilizada uma programação em Scratch em que o gato desaparecia da tela e também o bichinho interativo da Totetoy ${ }^{2}$.

Os sujeitos a partir de um ano experimentaram a programação em Scratch, mas posteriormente foram observados realizando imitações e utilizando o bichinho interativo da Totetoy.

Para as crianças de 2 anos foram oportunizadas situações de observação durante suas brincadeiras e atividades de classificação. $\mathrm{O}$ recurso tecnológico foi explorado no tablet com

\footnotetext{
${ }^{1}$ Programação em Scratch: (https://scratch.mit.edu/projects/108193596/)

${ }^{2}$ Bichinho interativo para smartphone: (http://www.totetoy.com.br)
} 
os aplicativos Classificação - Jogos para Crianças ${ }^{3}$ e Bimi Bo Formas e Cores ${ }^{4}$, em que as crianças deveriam levar as formas geométricas até os seus respectivos lugares.

Com as crianças a partir de 3 anos, foi realizada a prova em que era solicitado que o desenho de um triângulo. Ao explorar o recurso tecnológico, foi solicitado que utilizassem para desenhar o aplicativo Desenho para Crianças ${ }^{5}$, este permitia fazer desenhos, apagar e utilizar diferentes cores e formas de carimbos.

As crianças a partir de 4 anos realizaram a prova dos bastonetes ou das réguas, em que bastões de E.V.A deveriam ser organizados em forma de uma escada (crescente). Durante o uso do recurso tecnológico a mesma escada deveria ser montada utilizando o tablet.

Para as crianças de 5 anos a 7 anos, foram oportunizadas duas provas diferentes, a primeira que era a prova dos bastonetes ou réguas e a segunda que era a torre de hanói. Durante a exploração do recurso tecnológico, foi utilizado o aplicativo Tower of Hanoi ${ }^{6}$, em que as regras eram a mesma da torre original, porém ao movimentar o disco para um lugar impróprio, o mesmo acabava voltando para o lugar de origem, e era realizada a contagem de movimentações dos discos.

\section{Resultados}

Durante o momento em que as crianças faziam a exploração, procurou-se observar quais os elementos presentes nas tecnologias digitais que atraiam as crianças permitindo que elas percebessem coisas diferentes, que não percebiam durante a interação com uso de material concreto.

Dentre os elementos presentes e percebidos nas tecnologias digitais, destacam-se: a possibilidade de retomar/iniciar o aplicativo do lugar em que a criança parou, interação proporcionada pelo tablet ou smartphone, tecnologia toque tela, interface, feedbacks, desenvolvimento de habilidades cognitivas e motoras, e o grau de atenção dado pela criança durante a exploração.

Para Rogers (2012), esta afinidade justifica-se pelo fato de que as crianças estão imersas em um mundo de mídias interativas e diversos recursos tecnológicos. Em suas casas, na escola e em diferentes lugares, estão acostumadas a utilizar ferramentas digitais, que atualmente já fazem parte da sua cultura.

Os dispositivos favoritos das crianças para explorar são os tablets, demonstram preferência por explorá-lo, porque estes recursos, pelo olhar delas, possuem um tamanho de tela adequado, apresentam maior facilidades de manipulação devido à tecnologia toque tela $\mathrm{e}$ ainda pela praticidade de poder levá-lo por todos os cantos da casa e até mesmo durante passeios e atividades externas (Chaudron, 2015).

Em geral, na interação dos sujeitos, foi possível verificar que todos estavam desenvolvendo diferentes capacidades cognitivas, mas, também, que a preferência e a atração aconteciam pela forma com que a interface apresentava os aplicativos explorados, pois,

\footnotetext{
${ }^{3}$ Aplicativo Classificação - Jogos para crianças (https://play.google.com/store/www.apps/details?id=.andrey.sorterfree)

${ }^{4}$ Bimi Bo formas e cores (https://play.google.com/store/apps/details?id=com. bimiboo.playandlearn)

${ }^{5}$ Desenho pra crianças: (https://play.google.com/store/apps/details?id=com.iskander.drawforkids)

${ }^{6}$ Tower of Hanoi: (https://play.google.com/store/apps/details?id=johan.moller.towerofhanoi)
} 
conforme Rogers (2012), às experiências com as tecnologias digitais são mais agradáveis e envolventes.

Para todos os 16 (dezesseis) sujeitos, a interface mostrou-se muito importante, pois possibilitava perceber as cores, efeitos visuais, sonoros, visualizar relações espaciais e também temporais, situações estas que nem sempre eram percebidas da mesma forma ao utilizar o material concreto.

Outro fator que se demonstrou pertinente para o fato de as crianças quererem manipular as tecnologias digitais foi que, como já haviam utilizado em outros momentos, a utilização estava associada a brincar, como uma forma de se divertir e uma fonte de entretenimento, situação esta que também é afirmada por Chaudron (2015).

\section{Considerações finais}

Constatou-se ao observar os 16 sujeitos durante o desenvolvimento desta pesquisa que quando manipulavam situações com os recursos tecnológicos percebiam as coisas de modo diferente do que quando exploravam as mesmas situações com o uso de material concreto. Outro aspecto observado foi que os sujeitos se sobressaiam ao manipular os recursos tecnológicos, e demonstravam ter preferência ao manipular o mesmo.

Pelo olhar das crianças as tecnologias parecem ser mais interessante, fazendo com que prestassem mais atenção, ficassem mais atentos e buscassem receber feedbacks dos aplicativos, o que não acontecia quando estavam em contato com o material concreto. Pois durante esta interação necessitavam do adulto para retomar regras e fazer a contagem de pontuação. Adicionalmente, o uso de tablet, por ser um dispositivo compacto, possibilitou que as crianças pudessem explorá-lo com mais facilidade e que percebessem determinados acontecimentos que com o material concreto não foi possível observar.

Deste modo, proporcionar a exploração de recursos tecnológicos, tendo objetivos bem definidos pode conduzir a criança a desenvolver-se cognitivamente, de forma mais agradável e instigante, apresentando suportes a cognição e despertando coisas na criança que o material concreto não possibilita.

\section{Referências}

CETIC, (2017). Pesquisa TIC Kids Online Brasil 2016 - Pesquisa sobre o uso de Internet por crianças e adolescentes no Brasil 2016. Centro Regional de Estudos para o Desenvolvimento da Sociedade da Informação. Org: Alexandre Barbosa. São Paulo. CHAUDRON, Stéphane.Young (2015). Children (0-8) and Digital Technology: A qualitative exploratory study across seven countries. JRC Science and polyce reports.

DELVAL, Juan (2002). Introdução à prática do método clínico: descobrindo o pensamento das crianças. Porto Alegre: Artmed.

PIAGET, J. INHELDER, B (1985). O desenvolvimento das Quantidades Físicas na Criança: conservação e otimismo. Tradução de Christiano Monteiro Oiticica. 2 edição, Rio de Janeiro, Zahar; Brasília, INL.

PIAGET, J. SZEMINSKA (1975). A gênese do número na criança. Tradução de Christiano Monteiro Oiticica. $2^{\mathrm{a}}$ ed. Rio de Janeiro, Zahar; Brasilia, INL.

ROGERS; Fred (2012). Technology and Interactive Media as Tools in Early Childhood Programs Serving Children from Birth through Age 8. Positions State Ment Adopt, Ed, January. 